\title{
The Proportion and Prognostic Significance of T-Regulatory Cells in Patients with Gynecological Cancers: A Systematic Review and Meta-Analysis
}

\author{
Jiali Hu, Xirong Wu, Pengzhu Huang, Fei Teng, Yingmei Wang ${ }^{\bowtie}$, Fengxia Xue ${ }^{\bowtie}$ \\ Department of Obstetrics and Gynecology, Tianjin Medical University General Hospital, 154 Anshan Road, He Ping District, Tianjin 300052, China. \\ $\triangle$ Corresponding authors: Fengxia Xue, E-mail: fengxiaxue1962@gmail.com; Yingmei Wang, E-mail: wangyingmei1978@126.com \\ (c) The author(s). This is an open access article distributed under the terms of the Creative Commons Attribution License (https://creativecommons.org/licenses/by/4.0/). \\ See http://ivyspring.com/terms for full terms and conditions.
}

Received: 2019.11.26; Accepted: 2020.02.03; Published: 2020.03.05

\begin{abstract}
Objective: Multiple reports have described the proportion of T-regulatory cells (Tregs) in peripheral blood (PB) and tissues in patients with gynecological cancers (GCs) with controversial results. Thus, the aim of this study was to investigate the proportion of Tregs and its prognostic survival role in GCs patients.

Methods: We performed a comprehensive search from database inception for all studies presenting changes of Tregs in GCs patients versus controls to evaluate the pooled standardized mean differences (SMD) with $95 \%$ confidence intervals $(95 \% \mathrm{Cl})$. And hazard ratios $(\mathrm{HRs})$ with $95 \% \mathrm{Cl}$ were recorded if available to determine the prognostic significance of Tregs.

Results: Totally, 22 studies were included. Compared with controls, GCs patients had a higher proportion of Tregs in PB (SMD $=2.32,95 \% \mathrm{Cl}=1.47$ to $3.17, \mathrm{P}=0.000)$ as well as in tissues (SMD $=3.47,95 \% \mathrm{Cl}=0.77$ to $6.18, P=0.012$ ). Furthermore, more significant elevated frequency of Tregs was observed in GCs patients with advanced stage than those in the early stage in both PB and tissues. However, no association was found between Tregs and survival of GCs patients with an HR of $1.34(95 \% \mathrm{Cl}=0.96$ to $1.88, P=0.09)$.

Conclusions: Compared to controls, proportion of Tregs in PB and tissues was both higher among GCs patients, and it can be considered as a clinical biomarker for screening and prediction of clinical characteristics of GCs patients. But larger researches with rigorous design should be carried to explore the deep mechanisms of Tregs in GCs.
\end{abstract}

Key words: Gynecological cancer; T-regulatory cell; Proportion; Prognosis; Meta-analysis

\section{Introduction}

With roughly estimated 109,000 new cases and 33,100 deaths in 2019 in the United States, gynecological cancers (GCs) are considered as the fourth most frequent cancers in women nowadays, mostly including ovarian cancer (OC), endometrial cancer (EC), and cervical cancer (CC) [1]. Therefore, more researchers were focusing on exploring more effective therapies and underlying mechanisms of GCs in order to improve patients' survival and alleviate economic burden on the national health care system [2-4]. Tumor immunity, capacity of immune response to tumor, has aroused much attention with its undiscovered potential immunomodulatory properties on tumor progression [5]. Undoubtedly, it also performed well in GC [6]. T cells were the predominant kinds of immune cells which played vital roles in balancing tumor immune homeostasis between immune response and immune tolerance with respect to recent clinical developments of immunotherapies [7-9]. T-regulatory cells (Tregs), a highly enriched $\mathrm{T}$ cells subset in tumor microenvironment, were considered to be important mediators resulting in the failure of human antitumor immune response in most kinds of cancers, such as breast cancer, liver cancer, and lung cancer [10-12].

However, answer to the question "whether Tregs perform as inhibitors or promoters in the development of GCs through shaping immunologic tolerance and ignorance" is still ambiguous. Some of the previous studies confirmed that patients with GCs 
had increased numbers of peripheral circulating and tumor infiltration Tregs, especially in those with advanced stages, high grades, poor differentiation, and unfavorable survival [13-19]. In contrast, Saladin Sawan and colleagues reported fewer Tregs in patients with EC than benign controls [20]. Further study also identified the accumulation of Tregs in tumor-draining lymph nodes from OC patients was lower than those from control nodes, and it presented less frequent in advanced stage (III and IV) as compared with early stage (I and II) surprisingly [21]. Additionally, Ninke Leffers et al. added the reality that an increased number of Tregs indicated improved survival of OC patients [14]. Generally, roles of Tregs in GCs have been a longstanding topic of debate which was complicated and controversial. Thus, we conducted a systematic review and meta-analysis aiming to evaluate the different proportion of Tregs between GCs patients and controls and discover its potential clinical and prognostic implications.

\section{Methods}

\section{Search strategy and selection criteria}

This analysis was conducted in accordance with the Preferred Reporting Items for Systematic Reviews and Meta-Analyses (PRISMA) Statement [22]. An electronic search of the following databases from inception to June 25, 2019 was undertaken without language restrictions for studies in human of circulating and tumor infiltration Tregs in patients with GCs: PubMed, EMBASE, Web of Science, Cochrane Library, Scopus, SpringerLink, and ScienceDirect. The keywords of the search used were as follows: ("endometrial neoplasm" or "endometrial carcinoma" or "endometrial cancer" or "endometrium cancer" or "endometrium carcinoma" or "cancer of the endometrium" or "carcinoma of endometrium" or "uterine neoplasm" or "corpus uteri cancer" or "uterine cancer" or "uterine carcinoma"), ("ovarian cancer" or "carcinoma of the ovary" or "cancer of the ovary" or "ovarian carcinoma" or "ovarian neoplasms"), ("uterine cervical neoplasms" or "cervical cancer" or "carcinoma of the cervix" or "cancer of the cervix" or "cervical carcinoma" "cervical neoplasms"), and ("T-Lymphocytes, Regulatory" or "regulatory $\mathrm{T}$ cells" or Treg or $\mathrm{CD}^{+}{ }^{+} \mathrm{CD} 25^{+} \mathrm{FoxP}^{+}$or $\left.\mathrm{CD} 4{ }^{+} \mathrm{CD} 25^{+}\right)$. And searches on $\mathrm{MeSH}$ terms were added if available. Additionally, we also carefully scrutinized the reference lists of key publications to find all potentially relevant studies to broaden the scope of search. Since the study was not conducted on patients, no informed consent or ethical committee approval was needed.

\section{Inclusion and exclusion criteria}

Inclusion criteria were as follows: (1) original studies; (2) researches on human; (3) full text can be found; (4) studies with a title or abstract including GCs and Tregs; (5) accessible proportion of circulating or tumor infiltration Tregs as mean \pm standard deviation (SD) were evaluated using flow cytometry or immunohistochemical in GCs patients; and (6) availability of a hazard ratio (HR) and $95 \%$ confidence interval $(95 \% \mathrm{CI})$ for survival. No limitation was applied for the subtype of GCs, severities of the cancers, disability level, as well as sex and race of the study subjects.

Excluded criteria were as follows: (1) reviews, case reports, conference abstracts, proposals, and letters to editors; (2) duplicate publications and overlapping data from different databases; (3) special unusual types of Tregs; (4) hematological malignancies since these tumors were derived from the immune cells; and (5) no sufficient data can be extracted for later evaluation.

Two reviewers evaluated the titles and assessed the full text of all articles independently to assess eligibility. Disagreement was resolved by consensus.

\section{Data extraction}

The data and detailed information about the studies meeting the inclusion criteria were extracted by two independent reviewers via a predefined data extraction form. And quality of the eligible studies was evaluated based on the Newcastle-Ottawa Quality Assessment Scale (NOS) including three parameters: selection, comparability, and exposure [23]. The predefined data extraction form included name of the first author, year of publication, country of the study, types of GCs, numbers and mean age of GCs patients and controls, International Federation of Gynecology and Obstetrics (FIGO) stage or clinical stage, pathologic grade, sources of samples, detection methods, the definitions of Tregs used, and scores of NOS. Importantly, the proportion of circulating and tumor infiltration Tregs was recorded clearly. And HR was extracted preferentially from multivariable analyses when available. Otherwise, HR from univariate analyses was extracted. Corresponding authors were contacted to clarify any missing and ambiguous data.

\section{Statistical analysis}

Stata version 12 software was employed to compute calculations and prepare graphs. We assessed the status of Tregs in the peripheral blood (PB) and tissues of patients with GCs as continuous outcomes, and calculated pooled estimates of the standardized mean differences (SMD) with 95\% CI of 
the proportion of Tregs to present its difference between GCs patients and controls. Additionally, pooled HR with $95 \%$ CI was computed and weighted using generic inverse-variance to evaluate the prognostic significance of Tregs in GCs patients. Chi-squared $\mathrm{Q}$ test and $I^{2}$ statistics were used to assess heterogeneity. When $P<0.1$ or $I^{2}>50 \%$, the heterogeneity was considered significant moderate-tohigh and a random effect model was used. Otherwise, a fixed effect model was used. Subgroup analysis and sensitivity analysis were carried out to investigate the potential effects of study characteristics and certain single study that may influence the final results. Possibility of publication bias was assessed by constructing a funnel plot whose asymmetry was later evaluated using Begg's and Egger's tests to determine each study's effect against standard error. $P<0.05$ was considered significant.

\section{Results}

\section{Study characteristics}

The flow chart of the article search and inclusion process was detailed in Figure 1. Base on this search strategy, we identified 2604 studies, of which 22 studies were included in the final meta-analytical processes involving 2115 GCs patients and 470 controls. Main characteristics of the included studies were listed in Table 1 . All studies were retrospective researches including 12 of OC, 6 of CC, and 4 of EC. The recruitment of most studies (14 studies) were consecutive with the remainder being unknown. Average NOS score of the included studies was 6.91 (range from 5 to 9). Samples from PB and tissues were mostly tested by flow cytometry and immunohistochemistry.

Table 1. Characteristics of the included studies

\begin{tabular}{|c|c|c|c|c|c|c|c|c|c|c|c|c|c|}
\hline $\begin{array}{l}\text { First author and } \\
\text { year }\end{array}$ & Country & $\begin{array}{l}\text { Types } \\
\text { of GCs }\end{array}$ & $\mathrm{PN}$ & $\begin{array}{l}\text { Age of } \\
\text { Patients }\end{array}$ & $\mathrm{CN}$ & $\begin{array}{l}\text { Age of } \\
\text { Controls }\end{array}$ & FIGO/Clinical stage & Pathologic grade & $\begin{array}{l}\text { Source of } \\
\text { samples }\end{array}$ & $\mathrm{DM}$ & Definitions of Tregs & NS & Refs \\
\hline $\begin{array}{l}\text { Ekaterina S. } \\
\text { Jordanova } 2008\end{array}$ & UK & $\mathrm{CC}$ & 115 & $\begin{array}{l}48.5 \\
(24-87)\end{array}$ & 9 & $46(31-60)$ & IB1 (55), IB2/II (60) & NA & Tissues & QFEI & FoxP3 $^{+}$ & 8 & [13] \\
\hline $\begin{array}{l}\text { Walayat Shah } \\
2011\end{array}$ & China & $\mathrm{CC}$ & 40 & $\begin{array}{l}47 \\
(32-70)\end{array}$ & NA & NA & II (10), III (30) & NA & Tissues & IHC & $\mathrm{CD}^{+}{ }^{+} \mathrm{FoxP}^{+}$ & 5 & [19] \\
\hline Yan Zhang 2011 & China & $\mathrm{CC}$ & 49 & $\begin{array}{l}44 \\
(34-70)\end{array}$ & 28 & $42(26-67)$ & I (34), II (15) & $\begin{array}{l}\text { G1 (8), G2 (19), G3 } \\
(22)\end{array}$ & PBMCs & $\mathrm{FC}$ & $\mathrm{CD}_{4}{ }^{+} \mathrm{CD} 25^{+} \mathrm{FoxP}^{+}+$ & 8 & [17] \\
\hline $\begin{array}{l}\text { Zhifang Chen } \\
2013\end{array}$ & China & $\mathrm{CC}$ & 65 & $\begin{array}{l}45.50 \pm \\
6.12\end{array}$ & 40 & $\begin{array}{l}45.35 \pm \\
6.17\end{array}$ & I (26), II (39) & $\begin{array}{l}\text { G1 (11), G2 (21), G3 } \\
\text { (33) }\end{array}$ & PBMCs & $\mathrm{FC}$ & $\mathrm{CD}_{4}{ }^{+} \mathrm{CD} 25^{+} \mathrm{FoxP}^{+}+$ & 9 & [24] \\
\hline $\begin{array}{l}\text { Li-xin Zhang } \\
2014\end{array}$ & China & $\mathrm{CC}$ & 30 & NA & 20 & NA & NA & NA & PBL & $\mathrm{FC}$ & $\mathrm{CD}_{4}+\mathrm{CD} 25^{+} \mathrm{FoxP}^{+}$ & 5 & [25] \\
\hline $\begin{array}{l}\text { Beibei Wang } \\
2018\end{array}$ & China & $\mathrm{CC}$ & 70 & $\begin{array}{l}50.5 \pm \\
11.61\end{array}$ & 70 & $48.8 \pm 9.5$ & I (9), II (45), III (16) & NA & PB & $\mathrm{FC}$ & $\mathrm{CD} 4{ }^{+} \mathrm{CD} 25^{+}$ & 8 & [26] \\
\hline $\begin{array}{l}\text { Saladin Sawan } \\
2011\end{array}$ & UK & $\mathrm{EC}$ & 24 & $\begin{array}{l}66 \\
(44-92)\end{array}$ & 21 & $44(35-80)$ & I (13), II (4), III (7) & G1 (7), G2 (5), G3 (6) & PBMCs & $\mathrm{FC}$ & $\mathrm{CD}_{4}+\mathrm{FoxP}^{+}$ & 8 & [20] \\
\hline $\begin{array}{l}\text { Wataru } \\
\text { Yamagami } 2011\end{array}$ & Japan & EC & 53 & $\begin{array}{l}58 \\
(39-81)\end{array}$ & NA & NA & $\begin{array}{l}\text { I (23), II (4), III (23), IV } \\
(3)\end{array}$ & $\begin{array}{l}\text { G1 (25), G2 (13), G3 } \\
\text { (12), Others (3) }\end{array}$ & Tissues & IHC & $\mathrm{CD}^{+}{ }^{+} \mathrm{FoxP}^{+}$ & 6 & [16] \\
\hline $\begin{array}{l}\text { Kirsten Kübler } \\
2014\end{array}$ & $\begin{array}{l}\text { German } \\
\mathrm{y}\end{array}$ & $\mathrm{EC}$ & 163 & $\begin{array}{l}68 \pm \\
10.37\end{array}$ & NA & NA & $\begin{array}{l}\text { I (128), II (17), III (12), IV } \\
(6)\end{array}$ & $\begin{array}{l}\text { G1 (15), G2 (114), G3 } \\
\text { (34) }\end{array}$ & Tissues & IHC & FoxP3 $^{+}$ & 5 & [27] \\
\hline $\begin{array}{l}\text { Wenjing Zhang } \\
2014\end{array}$ & China & EC & 64 & $\begin{array}{l}55 \\
(31-80)\end{array}$ & 26 & $45(26-67)$ & $\begin{array}{l}\text { I (50), II (5), III-IV (6), } \\
\text { Unknown (3) }\end{array}$ & $\begin{array}{l}\text { G1 (30), G2 (15), G3 } \\
\text { (10), Unknown (9) }\end{array}$ & PBMCs & $\mathrm{FC}$ & $\mathrm{CD}_{4}{ }^{+} \mathrm{CD} 25^{+} \mathrm{FoxP}^{+}$ & 8 & [28] \\
\hline $\begin{array}{l}\text { Tyler J Curiel } \\
2004\end{array}$ & USA & OC & 70 & $\begin{array}{l}63.2 \\
(39-77)\end{array}$ & 5 & NA & $\begin{array}{l}\text { I (7), II (7), III (41), IV } \\
(15)\end{array}$ & $\begin{array}{l}\text { G1 (7), G2 (8), G3 } \\
\text { (55) }\end{array}$ & Tissues & IFT & $\mathrm{CD}^{+}{ }^{+} \mathrm{CD} 4{ }^{+} \mathrm{FoxP}^{+}$ & 7 & [21] \\
\hline Eiichi Sato 2005 & Japan & OC & 117 & $\begin{array}{l}62 \\
(33-89)\end{array}$ & NA & NA & $\begin{array}{l}\text { I (5), II (7), III (91), IV } \\
(12), \text { NA (1) }\end{array}$ & $\begin{array}{l}\text { G1 (8), G2 (4), G3 } \\
(105)\end{array}$ & Tissues & IHC & $\mathrm{CD}_{25}{ }^{+} \mathrm{FoxP} 3^{+}$ & 6 & [29] \\
\hline $\begin{array}{l}\text { Ninke Leffers } \\
2009\end{array}$ & $\begin{array}{l}\text { Netherla } \\
\text { nds }\end{array}$ & OC & 306 & $\begin{array}{l}57.2 \pm \\
13.5\end{array}$ & NA & NA & $\begin{array}{l}\text { I (67), II (24), III (171), IV } \\
(42), \text { NA (2) }\end{array}$ & $\begin{array}{l}\text { G1 (52), G2 (80), G3 } \\
\text { (135), UD (14), } \\
\text { Missing (25) }\end{array}$ & Tissues & IHC & FoxP3 $^{+}$ & 6 & [14] \\
\hline $\begin{array}{l}\text { Jason C. Barnett } \\
2010\end{array}$ & USA & OC & 232 & $\begin{array}{l}58 \\
(19-88)\end{array}$ & NA & NA & $\begin{array}{l}\text { I (24), II (13), III (127), IV } \\
(27), \text { Unknown (2) }\end{array}$ & $\begin{array}{l}\text { Borderline (39), G1 } \\
\text { (20), G2 (90), G3 (83) }\end{array}$ & Tissues & IHC & FoxP3 $^{+}$ & 6 & [15] \\
\hline $\begin{array}{l}\text { Nasrollah Erfani } \\
2014\end{array}$ & Iran & OC & 17 & $\begin{array}{l}50.3 \pm \\
11.6\end{array}$ & 20 & $49.8 \pm 8.0$ & I (3), II (3), III (8), IV (3) & NA & PBMCs & $\mathrm{FC}$ & $\mathrm{CD}_{4}{ }^{+} \mathrm{CD} 25^{+} \mathrm{FoxP}^{+}+$ & 9 & [18] \\
\hline $\begin{array}{l}\text { Keith L. } \\
\text { Knutson } 2015\end{array}$ & USA & $\mathrm{OC}$ & 348 & $\begin{array}{l}63 \\
(28-86)\end{array}$ & NA & NA & $\begin{array}{l}\text { I (41), II (15), III (265), IV } \\
(84)\end{array}$ & $\begin{array}{l}\text { G1 (10), G2 (393), G3 } \\
\text { (2) }\end{array}$ & Tissues & IHC & $\mathrm{CD}_{4}+\mathrm{CD} 25^{+} \mathrm{FoxP}^{+}$ & 5 & [30] \\
\hline Qinyi Zhu 2016 & China & OC & 40 & NA & 20 & NA & $\begin{array}{l}\text { I (11), II (9), III (19), IV } \\
(1)\end{array}$ & $\begin{array}{l}\text { G1 (1), G2 (18), G3 } \\
(21)\end{array}$ & Tissues & IFT & $\mathrm{CD}^{+}{ }^{+} \mathrm{FoxP}^{+}$ & 5 & [31] \\
\hline Meng Wu 2017 & China & OC & 61 & $\begin{array}{l}48.22 \pm \\
9.60\end{array}$ & 30 & NA & I-II (12), III-IV (49) & NA & PBMCs & $\mathrm{FC}$ & $\mathrm{CD}_{4}{ }^{+} \mathrm{CD} 25^{+} \mathrm{FoxP}^{+}$ & 8 & [32] \\
\hline Qinyi Zhu 2017 & China & OC & 126 & $\begin{array}{l}\text { Mean = } \\
51.4\end{array}$ & 26 & $\begin{array}{l}\text { Mean }= \\
52.15\end{array}$ & $\begin{array}{l}\text { I (34), II (30), III (61), IV } \\
\text { (1) }\end{array}$ & $\begin{array}{l}\text { G1 (12), G2 (37), G3 } \\
\text { (77) }\end{array}$ & Tissues & IFT & $\mathrm{CD}^{+}{ }^{+} \mathrm{FoxP}^{+}$ & 6 & [33] \\
\hline $\begin{array}{l}\text { Rikki A. } \\
\text { Cannioto } 2017\end{array}$ & USA & OC & 71 & $\begin{array}{l}58.1 \pm \\
11.0\end{array}$ & 101 & $57.2 \pm 10.9$ & NA & NA & PBMCs & $\mathrm{FC}$ & $\begin{array}{l}\mathrm{CD}^{+}{ }^{+} \mathrm{CD} 4{ }^{+} \mathrm{CD} 25^{+} \mathrm{Fox} \\
\mathrm{P}^{+}\end{array}$ & 7 & [34] \\
\hline Xing Ke 2018 & China & OC & 34 & $56.3 \pm 6.8$ & 34 & $51.8 \pm 5.2$ & I-II (18), III-IV (16) & G1-G2 (20), G3 (14) & PBMCs & $\mathrm{FC}$ & $\begin{array}{l}\mathrm{CD} 44^{+} \mathrm{CD} 25^{\text {high }} \mathrm{CD} 127^{1} \\
\text { ow }\end{array}$ & 8 & [35] \\
\hline Li Li 2019 & China & OC & 20 & $45.5 \pm 7.8$ & 20 & $44.5 \pm 6.1$ & I-II (6), III-IV (14) & NA & PBMCs & $\mathrm{FC}$ & $\begin{array}{l}\mathrm{CD} 4{ }^{+} \mathrm{CD} 25^{+} \mathrm{CD} 127-\mathrm{C} \\
\mathrm{XCR}^{+}{ }^{+} \mathrm{Fox}^{+}{ }^{+}\end{array}$ & 9 & [36] \\
\hline
\end{tabular}

PN: number of patients; CN: number of controls; DM: detection methods; NS: scores of NOS; Ref: references; NA: not available; QFEI: quadruple fluorescent and enzymatic immunostaining; IHC: immunohistochemistry; PBMCs: peripheral blood mononuclear cells; FC: flow cytometry; PBL: peripheral blood lymphocyte; IFT:

immunofluorescence technique. 


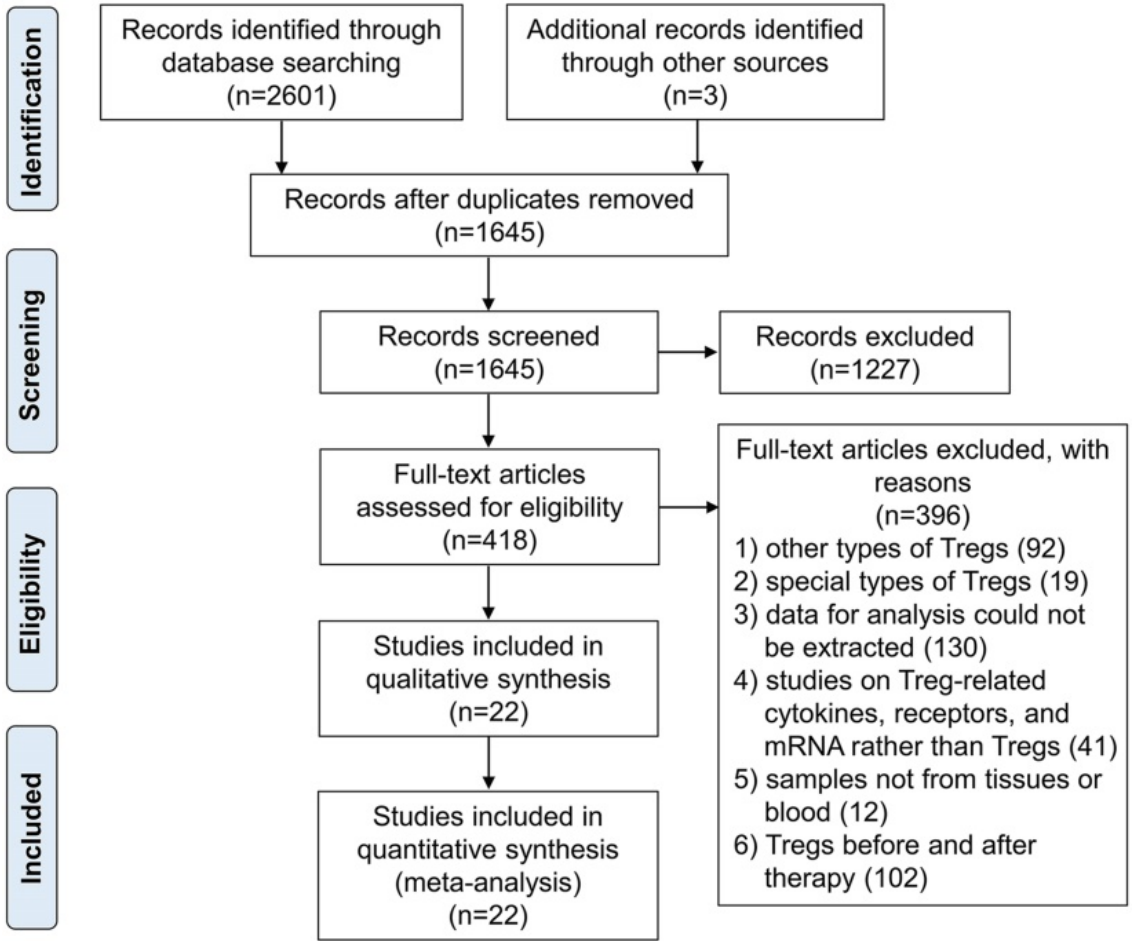

Figure 1. The flow chart of the article search and inclusion process following the PRISMA guidelines.

\section{The proportion of Tregs in GCs patients}

We initially compared the proportion of circulating Tregs in GCs patients with controls in 11 studies regardless of what kind of Tregs definitions had been used. Results in Figure 2A revealed that GCs patients had significantly increased frequency of Tregs in PB with SMD of 2.32 (95\% CI = 1.47 to 3.17, $P$ $=0.000)$. Since there was statistically significant heterogeneity among studies $\left(I^{2}=96 \%\right)$, random effect model was applied. Additionally, high abundance of Tregs was proved to be associated with advanced FIGO stage for the SMD of advanced stage versus early stage was $0.45(95 \% \mathrm{CI}=0.02$ to $0.87, P=0.038)$. As for the results of tissues, pool analysis of three studies showed there was also a significant increased proportion of tumor infiltration Tregs in GCs patients when compared with controls [SMD 3.47 (95\% CI = 0.77 to $6.18, P=0.012$ ) (Figure $2 \mathrm{~B}$ ). And similar to the results in $\mathrm{PB}$, a slight increase was observed when compared tumor infiltration Tregs in GCs patients on advanced stage with those on early stage $(\mathrm{SMD}=0.53$, $95 \% \mathrm{CI}=0.25$ to $0.81, P=0.000$ ).

\section{The prognostic value of Tregs on survival in GCs patients}

Six studies comprising 1119 patients were focused on results of Tregs in tissues which reported HR with 95\% CI for survival involving overall survival, disease-specific survival, and tumor associated survival. When we analyzed the prognostic significance of Tregs in GCs patients all together, the pooled $\mathrm{HR}$ was $1.34(95 \% \mathrm{CI}=0.96$ to $1.88, P=0.09)$ indicating their incapacity to predict the prognosis of GCs patients (Figure 2C). And four studies out of six all evaluated overall survival. In this condition, we also found no statistically significant association between tumor infiltration Tregs and GCs according to the pooled $\mathrm{HR}$ of $1.13(95 \% \mathrm{CI}=0.98$ to $1.30, P=$ $0.08)$.

\section{Subgroup analysis}

Subgroup analysis was performed to explore the impact of presumptive potential factors including types of GCs, score of NOS, and definitions of Tregs, that may influence the final results (Table 2). Due to the limited studies of tissues, we only conducted subgroup analysis of studies in PB in detail. Similar to its general role in GCs, accumulation of circulating Tregs were also observed high in patients with OC and CC respectively, with SMD for OC $2.64,95 \% \mathrm{CI}=$ 1.20 to 4.08 and SMD for CC $2.72,95 \% \mathrm{CI}=1.90$ to 3.53. However, no statistical significance was found in EC with SMD of 1.07 (95\% CI $=-0.11$ to 2.25). When classified by NOS score, both subgroups presented high proportion of Tregs in GCs patients. Although different definitions of Tregs based on diverse markers may influence the pooled SMD, most kinds of definitions listed in Table 2 showed elevated numbers of circulating Tregs in GCs patients when compared to controls except $\mathrm{CD} 4^{+} \mathrm{FoxP}^{+}$. 
A

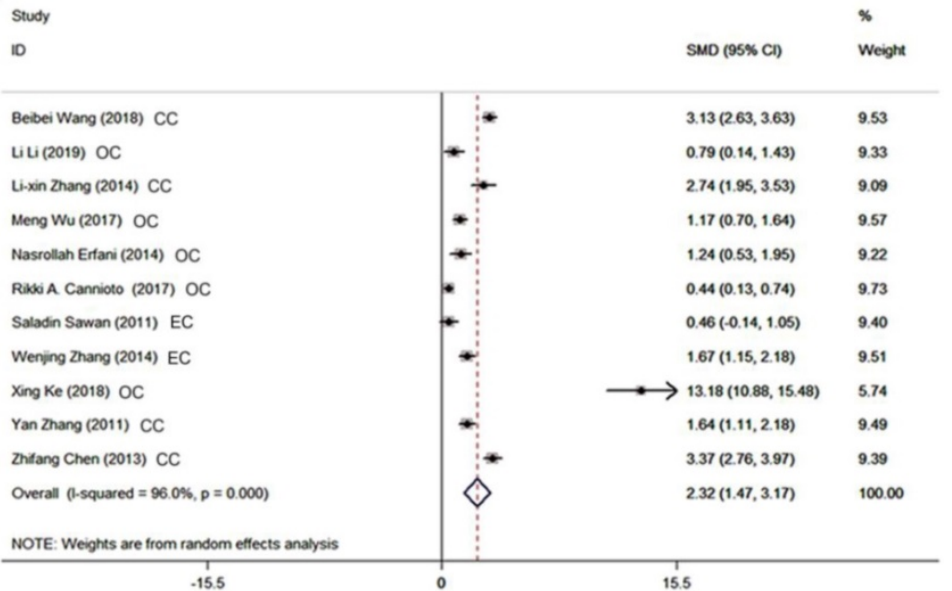

B

study

ID

SMD (95\% CI) Weight

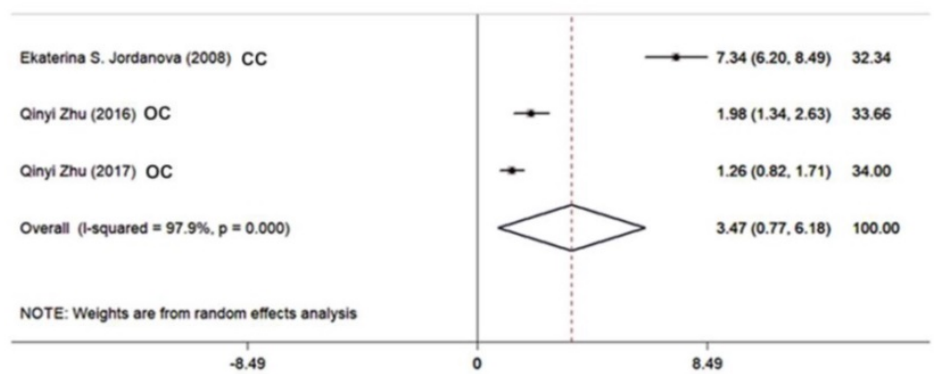

C

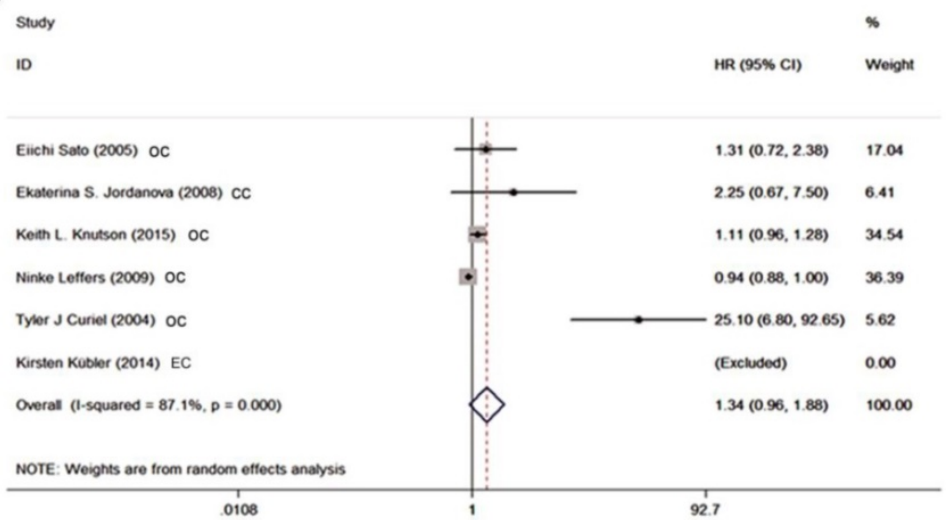

Figure 2. Forest plots showing the association between Tregs and GCs patients. A SMD of Tregs proportion in PB between GCs patients and controls. B SMD of Tregs proportion in tissues between GCs patients and controls. C HR for survival of Tregs in tissues greater than or less than the cutoff value.

A

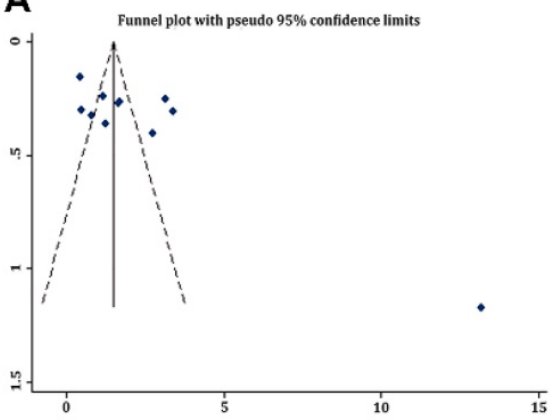

B

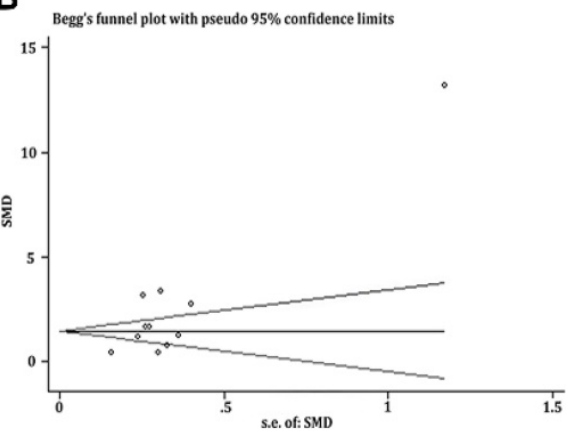

C

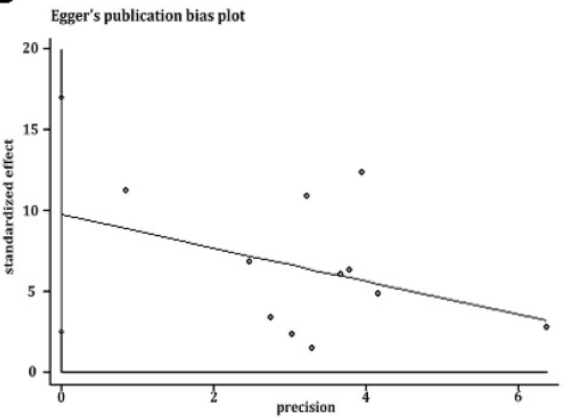

Figure 3. Evaluation of potential publication bias of the included researches on Tregs in PB. A Funnel plot. B Begg's funnel plot. C Egger's publication bias plot. 
Table 2. Subgroup analysis of SMD of Tregs in PB

\begin{tabular}{|c|c|c|c|c|c|}
\hline \multirow[t]{2}{*}{ Subgroup } & \multirow[t]{2}{*}{ No. of studies } & \multirow[t]{2}{*}{ SMD (95\% CI) } & \multirow[t]{2}{*}{ Overall effect $P$ value } & \multicolumn{2}{|c|}{ Test of heterogeneity } \\
\hline & & & & $I^{2}$ & $P$ value \\
\hline \multicolumn{6}{|l|}{ Types of GCs } \\
\hline OC & 5 & $2.64(1.20,4.08)$ & $P=0.000$ & $96.7 \%$ & $P=0.000$ \\
\hline $\mathrm{CC}$ & 4 & $2.72(1.90,3.53)$ & $P=0.000$ & $86.7 \%$ & $P=0.000$ \\
\hline $\mathrm{EC}$ & 2 & $1.07(-0.11,2.25)$ & $P=0.076$ & $88.9 \%$ & $P=0.003$ \\
\hline \multicolumn{6}{|l|}{ Scores of NOS } \\
\hline$\geq 7$ & 10 & $2.28(1.38,3.18)$ & $P=0.000$ & $96.3 \%$ & $P=0.000$ \\
\hline$<7$ & 1 & $2.74(1.95,3.17)$ & $P=0.000$ & NA & NA \\
\hline \multicolumn{6}{|l|}{ Definitions of Tregs } \\
\hline $\mathrm{CD} 4{ }^{+} \mathrm{CD} 25^{+}$ & 1 & $3.13(2.63,3.63)$ & $P=0.000$ & NA & NA \\
\hline $\mathrm{CD}_{4}^{+} \mathrm{FoxP}^{+}$ & 1 & $0.46(-0.14,1.05)$ & $P=0.131$ & NA & NA \\
\hline $\mathrm{CD}_{4}{ }^{+} \mathrm{CD} 25^{+} \mathrm{FoxP}^{+}+$ & 6 & $1.95(1.27,2.64)$ & $P=0.000$ & $87.8 \%$ & $P=0.000$ \\
\hline $\mathrm{CD}^{+}{ }^{+} \mathrm{CD} 4^{+} \mathrm{CD}_{25}{ }^{+} \mathrm{FoxP}^{+}$ & 1 & $0.44(0.13,0.74)$ & $P=0.005$ & NA & NA \\
\hline $\mathrm{CD}{ }^{+} \mathrm{CD} 25^{+} \mathrm{CD} 127-\mathrm{CXCR} 5+\mathrm{FoxP}^{+}$ & 1 & $0.79(0.14,1.43)$ & $P=0.017$ & NA & NA \\
\hline $\mathrm{CD} 4^{+} \mathrm{CD} 25^{\text {high }} \mathrm{CD} 127^{\text {low }}$ & 1 & $13.18(10.88,15.48)$ & $P=0.000$ & NA & NA \\
\hline
\end{tabular}

NA: not available

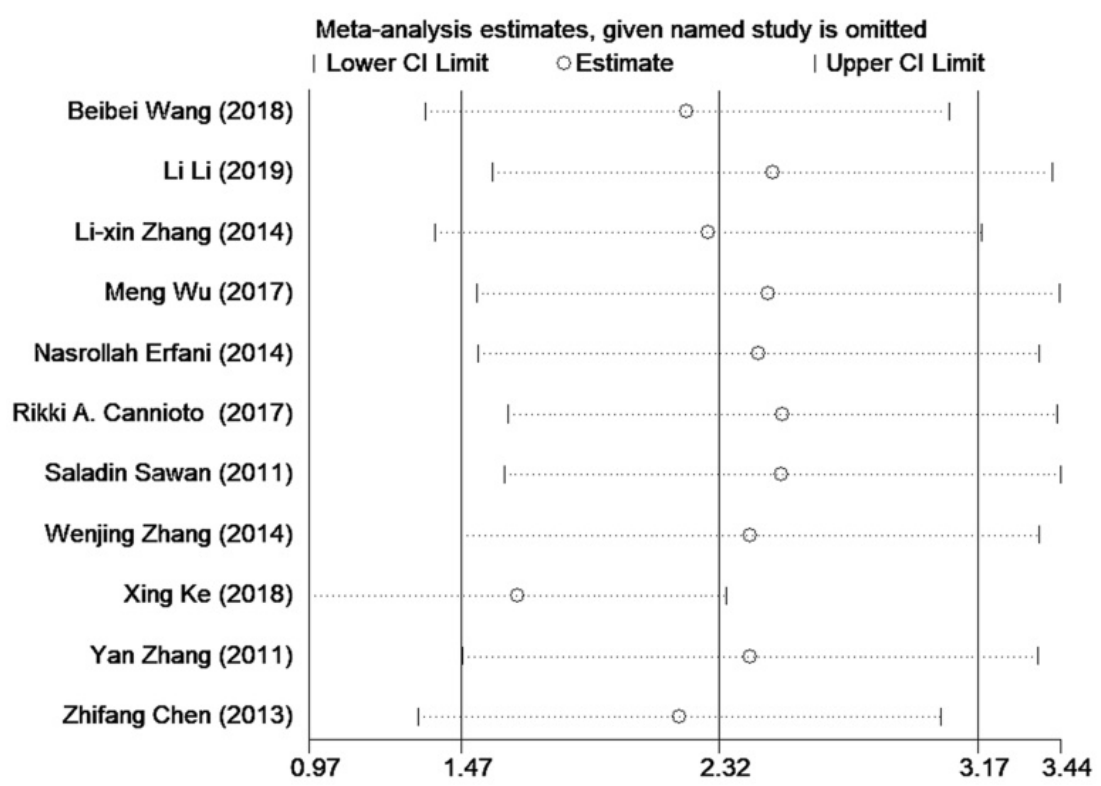

Figure 4. Sensitivity analysis of the included researches on Tregs in PB.

\section{Publication bias}

Funnel plot was depicted to describe the publication bias of researches on circulating Tregs, which showed slight significant asymmetry generally in Figure 3. That is to say, publication bias was not controlled well enough here. And results of Begg's test and Egger's test presented a consistent trend with what showed in funnel plot with both $P=0.014$ as well as asymmetric figures (see in Figure 3). Thanks to only three studies focusing on Tregs in tissues and only six studies aiming at the evaluation of HR, we didn't draw funnel plots of these issues.

\section{Sensitivity analysis}

Sensitivity analysis was conducted to explore the potential study that may contribute to data heterogeneity by omitting studies one by one. And no significant changes in the results were found except for excluding the study of Xing Ke (see in Figure 4).

\section{Discussion}

\section{Proportion of Tregs in PB was a biomarker for GCs}

Though there were substantial strides forward in the general understanding of Tregs that an elevated accumulation of it contributed to the development of some cancers, no consistent explicit roles of Tregs in GCs have been determined by previous reports yet $[11,12,37]$. That is to say, status of Tregs in GCs patients was still under debate. Therefore, we undertook a meta-analysis of 22 studies compromising three major types of GCs with 2115 patients to elucidate the clinical implications and prognostic value of Tregs in GCs. Our findings saw a consistent trend of increased frequency of Tregs in both PB and tissues which agreed with the phenomena that elevated accumulation of Tregs had the ability to hamper effective anti-tumor immune 
responses and maintain immunological tolerance in tumor-bearing hosts via co-operative interaction with certain other immune cells [38,39]. Of interest, frequency of Tregs in tissues was found mildly higher than those in PB (3.47 vs 2.32) for the reason that intra-tumoral Tregs originated primarily from certain kind of PB Tregs which were proved to be inclined to move into the lesion areas with the stimulation of inflammatory factors contributing to the progression of cancers [40]. And a study by Wu et al. also reported that imbalance of Tregs in the tumor microenvironment influenced the energetic metabolic processes including increased glucose uptake and fermentation of glucose to lactate, which had an important role in controlling cancer initiation and progression [41]. Therefore, no wonder proportion of Tregs within tumors presented at a higher level than those in $\mathrm{PB}$, which drove a state of immune disorders to promote the occurrence of GCs. Additionally, the phenomena that proportion of Tregs in GCs patients with advanced stage presenting higher than those with early stage, suggested the potential role of Tregs as a clinical biomarker to indicate poor prognosis which may help to aid patient stratification and tailor therapy for GCs patients.

\section{Prognostic value of tumor infiltration Tregs needed more investigations}

Relationship between survival of GCs patients and tumor infiltration Tregs was observed negative in general whatever on the basis of the ratio of Tregs/ $\mathrm{CD}^{+}$lymphocyte or Tregs/lymphocytes in this article. This was inconsistent with the conclusion drew by Shang B et al. that Treg infiltration was significantly associated with shorter overall survival in the majority of solid tumors, including cervical cancer [42]. The reason for this inconformity might lie in the fact that we analyzed HR rather than the odds ratio to evaluate the prognostic role of Tregs. The included literatures in Shang B et al.'s research and ours were also not the same. And HR was preferred to be applied in many survival analyses for it considered the time factor [43]. In this present meta-analysis, we hypothesized that the unexpected negative result might be influenced by the following reasons. Firstly, combined analysis might be highly influenced by different tumor site, severities of the disease, molecular subtype, and tumor stage $[17,28,36]$. Secondly, results of survival analysis were based on measurement of Tregs in tissues through immunohistochemistry which provided accurate positions but offered no exact total amount and ratio of Tregs $[13,27,30]$. Actually, flow cytometry was preferred under this condition, and it was more suitable to determine the cutoff values. And finally, included studies applied different definitions to identify Tregs leading to the insignificant difference in survival affected by Tregs $[14,29,30]$. Therefore, a correct and reasonable definition was expected to contain not only the classical distinct markers but also some markers to identify the biological function of Tregs. Additionally, values of cutoffs also played a vital role in determining the significance of Tregs in GC patients' survival. Of important, although cutoffs values of Tregs ratio determined mostly by the median values of immunostaining was reported to divide tumors into high and low frequency of Tregs group, the specific methods of how to group remained vague $[13,14,21,27,29,30]$. Thus, it was urgent and important for us to set up more well-designed and broader spectrum of subjects joined researches to clarify this issue.

\section{Subgroup analysis}

Summarized from the results of subgroup analysis, we found some interesting phenomena. Compared with controls, patients with $\mathrm{CC}$ and $\mathrm{OC}$ possessed a high proportion of Tregs in PB. Conversely, such situation didn't occur in those with EC [SMD 1.07 $(-0.11,2.25)]$. It was the limited total two of the included studies evaluating Tregs in EC that may cause this negative result [20,28]. Additionally, frequency of Tregs in PB was always reported to present a high trend in patients with GCs in spite of classification by different scores of NOS of studies. Moreover, the proportion of circulating Tregs identified by different definitions was all proved to be higher in GCs patients versus those without except for the definition as $\mathrm{CD}_{4}{ }^{+} \mathrm{FoxP}_{3}{ }^{+}$cells. But, most of the included researches applied $\mathrm{CD} 4^{+} \mathrm{CD} 25^{+} \mathrm{FoxP}^{+}$not $\mathrm{CD}^{+}{ }^{+} \mathrm{FoxP}^{+}$as the standard criterion to identify Tregs in this meta-analysis. How to define Tregs could be the key point to influence the results. Multiple reports had already described differentiative and functional properties of Tregs were dependent on the expression of the FoxP3, and consequently, FoxP3 was considered as the key intracellular molecule and specific marker for Tregs so far [44, 45]. While other opposite voices declared that FoxP3 couldn't be an exclusive marker for Tregs, since it was also upregulated in other activated immune cells [46]. Thus, it was significant for us to discover additional appropriate and precise markers to distinguish Tregs from other immune cells correctly to enhance the reliability of further studies. Besides, subgroup analysis of data on tissues infiltration Tregs was not performed because the included researches examining this ratio were too scarce. 


\section{Publication bias and sensitivity analysis}

Results of Begg's test and Egger's test based on data of Tregs in PB both suggested there was some publication bias which reminded us to interpret the final results with caution. This might be attributed to inclusion of small sample researches in this study. And positive results were more easily to be published than negative ones. Therefore, further studies with a larger spectrum of patients ought to be carried out, and those with negative results should be encouraged to be published. Additionally, the picture of sensitivity analysis demonstrated certain stabilization of our pooled results and the relatively high heterogeneity of pooled SMD was possibly due to study by Xing Ke. Therefore, we omitted this study to find that heterogeneity decreased from $96.0 \%$ to $94.1 \%$, and pooled SMD still had statistical meaning $[\mathrm{SMD}=1.65(95 \% \mathrm{CI}=0.97$ to 2.34$), P=0.000]$. This phenomenon confirmed the reliability of our primary results.

\section{Limitations}

Although we believed that the current meta-analysis provided some useful information, there were still some potential limitations should be addressed. Firstly, only summarized data rather than individual patient's data could be used. Secondly, heterogeneity in our study was substantial. So, it was cautious for us to interpret the results based on evaluation via a random effect model. Thirdly, we only included studies reporting on the values of SMD and HR, and consequently enormous publications reporting on the clinical and prognostic value of Tregs as odd ratios and relative risks were excluded. Fourth, proportion of Tregs in PB and tissues was nonspecific parameters, which may be influenced by concurrent conditions such as infections, inflammation, and medication, resulting in the confusion of Tregs' measurement. Fifth, we could not conduct subgroup analysis of different level of age, weight, pathologic grade, and tissues due to lack of sufficient original data from the included studies.

\section{Conclusion}

Generally, our findings clearly lent support to the theory that Tregs was a promising biomarker to distinguish patients with GCs from healthy controls and it also possessed the ability to indicate the clinical characteristics of patients. And independent cohorts of patients with a larger spectrum of patients and controls are expected to validate our results forcefully.

\section{Acknowledgements}

The authors thank Drs F. Xue and Drs Y. Wang
for directing this systematic review and meta-analysis. This study was supported by grants from the Natural Science Foundation of China (No. 81972448 and No. 81802617).

\section{Author Contributions}

$\mathrm{JH}$ : literature review and manuscript writing; XW: literature review; $\mathrm{PH}$ : data analysis and designation of figures; FT: designation of the tables; FX and YW: manuscript revision. FX and FT: providers of the funding for the project together.

\section{Competing Interests}

The authors have declared that no competing interest exists.

\section{References}

1. Siegel RL, Miller KD, Jemal A. Cancer statistics, 2019. CA: a cancer journal for clinicians. 2019; 69: 7-34.

2. Eisenhauer EA. Real-world evidence in the treatment of ovarian cancer. Annals of oncology : official journal of the European Society for Medical Oncology. 2017; 28: viii61-viii5.

3. George F. Sawaya KS-M, Miriam Kuppermann. Cervical Cancer Screening More Choices in 2019. JAMA. 2019; 321: 2018-9.

4. Lee YC, Lheureux S, Oza AM. Treatment strategies for endometrial cancer: current practice and perspective. Current opinion in obstetrics \& gynecology. 2017; 29: 47-58.

5. Wang HF, Wang SS, Huang MC, Liang XH, Tang YJ, Tang YL. Targeting Immune-Mediated Dormancy: A Promising Treatment of Cancer. Frontiers in oncology. 2019; 9: 498

6. Ventriglia J, Paciolla I, Pisano C, Cecere SC, Di Napoli M, Tambaro R, et al. Immunotherapy in ovarian, endometrial and cervical cancer: State of the art and future perspectives. Cancer treatment reviews. 2017; 59: 109-16.

7. Ostroumov D, Fekete-Drimusz N, Saborowski M, Kuhnel F, Woller N. CD4 and CD8 T lymphocyte interplay in controlling tumor growth. Cellular and molecular life sciences : CMLS. 2018; 75: 689-713.

8. $\mathrm{Yu} \mathrm{L}$, Wang J. T cell-redirecting bispecific antibodies in cancer immunotherapy: recent advances. Journal of cancer research and clinical oncology. 2019; 145: 941-56.

9. Jindal V, Arora E, Gupta S, Lal A, Masab M, Potdar R. Prospects of chimeric antigen receptor $\mathrm{T}$ cell therapy in ovarian cancer. Medical Oncology. 2018; 35:70.

10. Taylor NA, Vick SC, Iglesia MD, Brickey WJ, Midkiff BR, McKinnon KP, et al. Treg depletion potentiates checkpoint inhibition in claudin-low breast cancer. The Journal of clinical investigation. 2017; 127: 3472-83.

11. Edward Y. Woo CSC, Theresa J. Goletz, Katia Schlienger, Heidi Yeh, George Coukos, Stephen C. Rubin, Larry R. Kaiser, Carl H. June. Regulatory CD4(+)CD25(+) T cells in tumors from patients with early-stage non-small cell lung cancer and late-stage ovarian cancer. Cancer research. 2001; 61: 4766-72.

12. Shen $\mathrm{X}, \mathrm{Li} \mathrm{N}, \mathrm{Li} \mathrm{H}$, Zhang $\mathrm{T}$, Wang $\mathrm{F}, \mathrm{Li} \mathrm{O}$. Increased prevalence of regulatory $\mathrm{T}$ cells in the tumor microenvironment and its correlation with TNM stage of hepatocellular carcinoma. Journal of cancer research and clinical oncology. 2010; 136: 1745-54.

13. Jordanova ES, Gorter A, Ayachi O, Prins F, Durrant LG, Kenter GG, et al. Human leukocyte antigen class I, MHC class I chain-related molecule A, and $\mathrm{CD} 8+$ /regulatory T-cell ratio: which variable determines survival of cervical cancer patients? Clinical cancer research : an official journal of the American Association for Cancer Research. 2008; 14: 2028-35.

14. Ninke Leffers MJMG, Renske A. de Jong, Baukje-Nynke Hoogeboom, Klaske A. ten Hoor, Harry Hollema, H. Marieke Boezen, Ate G. J. van der Zee, Toos Daemen, Hans W. Nijman. Prognostic significance of tumor-infiltrating T-lymphocytes in primary and metastatic lesions of advanced stage ovarian cancer. Cancer immunology, immunotherapy : CII. 2009; 58: 449-59.

15. Barnett JC, Bean SM, Whitaker RS, Kondoh E, Baba T, Fujii S, et al. Ovarian cancer tumor infiltrating T-regulatory (T(reg)) cells are associated with a metastatic phenotype. Gynecologic oncology. 2010; 116: 556-62.

16. Yamagami W, Susumu N, Tanaka H, Hirasawa A, Banno K, Suzuki N, et al. Immunofluorescence-detected infiltration of $\mathrm{CD} 4+\mathrm{FOXP} 3+$ regulatory $\mathrm{T}$ cells is relevant to the prognosis of patients with endometrial cancer. International journal of gynecological cancer : official journal of the International Gynecological Cancer Society. 2011; 21: 1628-34.

17. Zhang Y, Ma D, Zhang Y, Tian Y, Wang X, Qiao Y, et al. The imbalance of Th17/Treg in patients with uterine cervical cancer. Clinica chimica acta; international journal of clinical chemistry. 2011; 412: 894-900.

18. Nasrollah Erfani MH-S, Somayeh Rezaeifard, Mohammadreza Haghshenas, Manoochehr Rasouli, Alamtaj Samsami Dehaghani. FoxP3+ regulatory T cells 
in peripheral blood of patients with epithelial ovarian cancer. Iran J Immunol. 2014; 11: 105-12.

19. Shah $W$, Yan $X$, Jing L, Zhou $Y$, Chen $H$, Wang Y. A reversed CD4/CD8 ratio of tumor-infiltrating lymphocytes and a high percentage of CD4(+)FOXP3(+) regulatory $\mathrm{T}$ cells are significantly associated with clinical outcome in squamous cell carcinoma of the cervix. Cellular \& molecular immunology. 2011; 8: 59-66

20. Sawan S, Burt DJ, Stern PL, Holland C, Elkord E. Circulating regulatory T cells in endometrial cancer: a role for age and menopausal status. Immunological investigations. 2011; 40: 62-75.

21. Curiel TJ, Coukos G, Zou L, Alvarez X, Cheng P, Mottram P, et al. Specific recruitment of regulatory $\mathrm{T}$ cells in ovarian carcinoma fosters immune privilege and predicts reduced survival. Nature medicine. 2004; 10: 942-9.

22. Liberati A, Altman DG, Tetzlaff J, Mulrow C, Gotzsche PC, Ioannidis JP, et al. The PRISMA statement for reporting systematic reviews and meta-analyses of studies that evaluate health care interventions: explanation and elaboration. Journal of clinical epidemiology. 2009; 62: e1-34.

23. Stang A. Critical evaluation of the Newcastle-Ottawa scale for the assessment of the quality of nonrandomized studies in meta-analyses. European journal of epidemiology. 2010; 25: 603-5.

24. Zhifang Chen, Nannan Pang, Rong Du, Wei Meng, Yuejie Zhu, Yi Zhang, et al. The Th17/Treg balance and the expression of related cytokines in Uygur cervical cancer patients. Diagnostic pathology. 2013; 8: 2-11.

25. Zhang LX, Liu ZN, Ye J, Sha M, Oian H, Bu XH, et al. Artesunate exerts an anti-immunosuppressive effect on cervical cancer by inhibiting PGE2 production and Foxp3 expression. Cell biology international. 2014; 38: 639-46.

26. Wang B, Wang H, Li P, Wang L, Liu H, Liu J, et al. Relationships of interleukin-10 with the regulatory $\mathrm{T}$ cell ratio and prognosis of cervical cancer patients. Clinics. 2018; 73: e679.

27. Kubler K, Ayub TH, Weber SK, Zivanovic O, Abramian A, Keyver-Paik MD, et al. Prognostic significance of tumor-associated macrophages in endometrial adenocarcinoma. Gynecologic oncology. 2014; 135: 176-83.

28. Zhang W, Hou F, Zhang Y, Tian Y, Jiao J, Ma D, et al. Changes of Th17/Tc17 and Th17/Treg cells in endometrial carcinoma. Gynecologic oncology. 2014; 132: 599-605.

29. Sato E, Olson SH, Ahn J, Bundy B, Nishikawa H, Qian F, et al. Intraepithelial CD8+ tumor-infiltrating lymphocytes and a high CD8+/regulatory T cell ratio are associated with favorable prognosis in ovarian cancer. Proceedings of the National Academy of Sciences of the United States of America. 2005; 102: 18538-43.

30. Knutson KL, Maurer MJ, Preston CC, Moysich KB, Goergen K, Hawthorne $\mathrm{KM}$, et al. Regulatory $\mathrm{T}$ cells, inherited variation, and clinical outcome in epithelial ovarian cancer. Cancer immunology, immunotherapy : CII. 2015; 64: 1495-504.

31. Zhu $\mathrm{Q}, \mathrm{Wu}, \mathrm{X}, \mathrm{Wu}, \mathrm{Y}$, Wang $\mathrm{X}$. Interaction between Treg cells and tumor-associated macrophages in the tumor microenvironment of epithelial ovarian cancer. Oncology reports. 2016; 36: 3472-8.

32. Wu $M$, Chen $X$, Lou J, Zhang $S$, Zhang $X$, Huang $L$, et al Changes in regulatory $\mathrm{T}$ cells in patients with ovarian cancer undergoing surgery: Preliminary results. International immunopharmacology. 2017; 47: 244-50.

33. Zhu $Q$, Wu X, Wang X. Differential distribution of tumor-associated macrophages and Treg/Th17 cells in the progression of malignant and benign epithelial ovarian tumors. Oncology letters. 2017; 13: 159-66.

34. Cannioto RA, Sucheston-Campbell LE, Hampras S, Goode EL, Knutson K, Ness $R$, et al. The Association of Peripheral Blood Regulatory T-Cell Concentrations With Epithelial Ovarian Cancer: A Brief Report. International journal of gynecological cancer : official journal of the International Gynecological Cancer Society. 2017; 27: 11-6.

35. Ke X, Shen L. Targeting cytokines secreted by CD4(+) CD25(high) CD127(low) regulatory $\mathrm{T}$ cells inhibits ovarian cancer progression. Scandinavian journal of immunology. 2018; 89: e12736.

36. Li L, Ma Y, Xu Y. Follicular regulatory $\mathrm{T}$ cells infiltrated the ovarian carcinoma and resulted in CD8 T cell dysfunction dependent on IL-10 pathway. International immunopharmacology. 2019; 68: 81-7.

37. Shen Z, Zhou S, Wang Y, Li RL, Zhong C, Liang C, et al. Higher intratumoral infiltrated Foxp3+ Treg numbers and Foxp3+/CD8+ ratio are associated with adverse prognosis in resectable gastric cancer. Journal of cancer research and clinical oncology. 2010; 136: 1585-95

38. Han S, Toker A, Liu ZQ, Ohashi PS. Turning the Tide Against Regulatory T Cells. Frontiers in oncology. 2019; 9: 279.

39. Okeke EB, Uzonna JE. The Pivotal Role of Regulatory T Cells in the Regulation of Innate Immune Cells. Frontiers in Immunology. 2019; 10: 680

40. Wang L, Simons DL, Lu X, Tu TY, Solomon S, Wang R, et al. Connecting blood and intratumoral Treg cell activity in predicting future relapse in breast cancer. Nature immunology. 2019.

41. Wu D. Innate and Adaptive Immune Cell Metabolism in Tumor Microenvironment. Advances in experimental medicine and biology. 2017; 1011: 211-23.

42. Shang B, Liu Y, Jiang SJ, Liu Y. Prognostic value of tumor-infiltrating FoxP3+ regulatory $\mathrm{T}$ cells in cancers: a systematic review and meta-analysis. Scientific reports. 2015; 5: 15179 .

43. Mehrotra DV, Zhang Y. Hazard ratio estimation and inference in clinical trials with many tied event times. Statistics in medicine. 2018; 37: 3547-56.

44. Najafi M, Farhood B, Mortezaee K. Contribution of regulatory T cells to cancer: A review. Journal of cellular physiology. 2019; 234: 7983-93.
45. Roncarolo MG, Gregori S. Is FOXP3 a bona fide marker for human regulatory T cells? European journal of immunology. 2008; 38: 925-7.

46. Togashi $Y$, Shitara K, Nishikawa $H$. Regulatory $T$ cells in cancer immunosuppression - implications for anticancer therapy. Nature reviews Clinical oncology. 2019; 16: 356-71. 